\title{
ANALISIS MOTIVASI BELAJAR SISWA MTS DALAM PEMBELAJARAN MATEMATIKA MATERI SEGITIGA DENGAN BERBANTUAN MEDIA JAVASCRIPT GEOGEBRA
}

\author{
Martin Bernard ${ }^{1}$, Arif Sunaryo ${ }^{2}$ \\ 1,2 IKIP Siliwangi, J1. Terusan Jendral Sudirman, Cimahi tengah, Kota Cimahi, Jawa Barat \\ pamartin23rnard@gmail.com
}

\begin{abstract}
This study discusses how students learn in triangle mathematics material with the help of geogebra applications. The research method uses descriptive qualitative. The subjects used in this study were class VII students totaling 25 students on triangle material. The instrument used was a learning motivation scale with 10 responses that had positive responses and negative responses. This statement is used to look for responses from respondents on student motivation in learning mathematics in triangle material with the help of geogebra applications. The results of this study indicate how students' learning on triangular material assisted by JavaScript-assisted geogebra applications shows positive results with an average publish response of $74.9 \%$ and is categorized as strong. The average obtained by each indicator of learning motivation questionnaire that has been given to each respondent.
\end{abstract}

Keywords: Analysis of concept errors, Trigonometry

\begin{abstract}
Abstrak
Penelitian ini bertujuan untuk menganalisis motivasi belajar siswa dalam pembelajaran matematika materi segitiga dengan berbantuan aplikasi geogebra. Metode penelitian menggunakan deskriptif kualitatif. Subjek yang digunakan dalm penelitian ini adalah siswa kelas VII sebanyak 25 orang siswa pada materi segitiga. Instrumen yang digunakan yaitu skala motivasi belajar dengan 10 pernyataan yang memiliki tanggapan positif maupun tanggapan negatif. Pernyataan tersebut digunakan untuk mencari tanggapan dari responden terhadap motivasi belajar siswa dalam pembelajaran matematika pada materi segitiga dengan berbantuan aplikasi geogebra. Hasil dari penelitian ini menunjukan bahwa motivasi belajar siswa pada materi segitiga dengan berbantuan aplikasi geogebra berbantuan JavaScript menunjukkan hasil positif dengan respon perolehan rata-rata presentase 74,9\% dan dikategorikan kuat. Rata-rata tersebut tersebut diperoleh oleh setiap indikator angket motivasi belajar yang telah diberikan kepada setiap responden.
\end{abstract}

Kata kunci: JavaScript, Geogebra, Motivasi belajar, Segitiga

\section{PENDAHULUAN}

Matematika merupakan salah satu jenis pengetahuan yang dibutuhkan manusia dalam menjalankan kehidupannya sehari-hari (Akbar,et. Al, 2018; Ayyubi, 2018; Sugandi, \& Akbar, 2019) atau sebagai pelayan ilmu untuk bidang lain (Wiliawanto, et. al, 2019; Isnaeni, et. al, 2019). Misalnya ketika berbelanja maka kita perlu memilih dan menghitung jumlah benda yang akan dibeli dan harga yang harus dibayar. Saat akan pergi, kita perlu mengingat arah jalan tempat yang akan didatangi, berapa lama jauhnya, serta memilih jalan yang lebih bisa cepat sampai di tujuan, dan lain-lain. Bila kita berpikir tentang matematika maka kita akan membicarakan tentang persamaan dan perbedaan, pengaturan informasi/data, memahami tentang angka, jumlah, pola-pola, ruang, bentuk, perkiraan dan perbandingan.

Matematika sebagai ilmu dasar dari segala bidang, merupakan hal yang sangat penting untuk dipelajari dan merupakan ilmu yang mendasari perkembangan ilmu pengetahuan dan teknologi. Oleh sebab itu matematika perlu diajarkan mulai dari tingkat dasar sampai tingkat perguruan tinggi. Menghadapi perkembangan ilmu pengetahuan dan teknologi yang begitu pesat saat ini, diperlukan 
sumber daya manusia yang handal dan mampu berkompetisi secara global. Kompetisi akan menjadi prinsip hidup dalam suatu masyarakat, karena keadaan dunia yang terbuka dan bersaing untuk mengejar kualitas dan keunggulan. Kemampuan manusia beradaptasi dilandasi oleh kemampuan berpikirnya yang melahirkan teknologi dan bentuk kehidupan sosial budayanya. Pembelajaran matematika perlu dirancang agar dapat mengakomodasi berbagai karakteristik siswa (Insani, et. al., 2019), Selain itu pembelajaran Matematika harus menekankan pada pemberian pengalaman belajar secara langsung melalui penggunaan dan pengembangan keterampilan proses dan sikap ilmiah. Sikap ilmiah biasa dikembangkan ketika siswa melakukan diskusi atau kerja kelompok karena pada saat itulah berlangsung kerjasama sehingga diperoleh pengetahuan yang lebih banyak.

Salah satu materi matematika yang diajarkan adalah segitiga. Siswa masih mengalami kesulitan dalam mempelajari segitiga. Berdasarkan penelitian yang dilakukan oleh Yuwono (2016) terdapat tiga jenis kesulitan belajar peserta didik dalam mengerjakan soal materi segtiga yaitu (a) kesulitan dalam memahami konsep serta definisi alas dan tinggi segitiga, serta peserta didik masih kesulitan dalam memahami konsep dua garis yang saling berpotongan dan menyebutkan hubungan antar sudut pada dua garis yang saling sejajar, (b) kesulitan dalam mengidentifikasi dan menyebutkan sifat-sifat yang meliputi kesulitan mengidentifikasi dan mengaitkan antara sifat segitiga samasisi dengan sifat segitiga samakaki, dengan menyebutkan bahwa segitiga samasisi bukan segitiga samakaki, (c) kesulitan dalam menemukan rumus yang meliputi kesulitan membuktikan jumlah besar sudut dalam suatu segitga adalah dan menemukan atau membuktikan rumus luas segitiga jika diketahui ukuran alas dan tingginya.

Kemampuan peserta didik menggunakan pengalaman atau pengetahuan yang telah mereka miliki untuk mengkonstruk (membangun) pengetahuan yang baru sangat dipengaruhi media pembelajaran yang digunakan. Kaino (2008) menjelaskan perangkat lunak memfasilitasi beberapa kegiatan belajar geometri, misalnya visualisasi dan konvensional dan dapat meningkatkan kemampuan peserta didik dalam hal pembuktian (Martinez, 2005). Gage and Berliner (Dwijanti, 2011) berpendapat bahwa membangun kreativitas merupakan salah satu dari tujuan mendasar diterapkannya pendekatan humanistik dalam pendidikan. Proses akomodasi dalam teori Piaget (Hidayat, 2004:7)

Sejalan dengan perkembangan ilmu pengetahuan dan teknologi, banyak bermunculan berbagai aplikasi yang dapat digunakan sebagai media pembelajaran. Menurut Kustandi \& Sutjipto (2011) dalam pembelajaran, media di fungsikan sebagai sarana untuk mencapai tujuan dari pembelajaran.Heris Hendriana, Martin Bernard dan M Afrilianto, (2016) mengatakan, "Penguasaan ICT mutlak diperlukan oleh guru dan siswa karena dapat membuat siswa lebih tertarik dan antusias dalam belajar", dan ICT dapat juga membantu kesulitan siswa dalam memahami matematika (Bernard, et, al, 2019) dan kebermanfaatan tekhnilogi di dunia pendidikan (Sopyan, et. al, 2019).

Salah satu contoh aplikasi matematika yang dapat digunakan sebagai media yang inovasi adalah aplikasi geogebra (Bernard \& Senjayawati, 2019; Puspitasari, et. Al, 2019; Senjayawati \& Bernard, 2018). Geogebra adalah software dinamis yang menggabungkan geometri, aljabar, dan kalkulus yang 
dapat digunakan sebagai alat bantu dalam pembelajaran matematika. Aplikasi ini dapat digunakan dimanapun dan kapanpun oleh guru maupun siswa.

Aplikasi yang diciptakan oleh Markus Hohenwarter mulai tahun 2001 ini dapat membuktikan berbagai konsep dasar matemaika terutama pada materi geometri. Dengan adanya pembuktian tersebut siswa diharapkan memiliki kecenderungan memandang matematika sebagai suatu yang dapat dipahami sehingga siswa merasa yakin atau percaya diri dengan pengetahuan yang diperolehnya

Menurut Hohenwarter (Mahmudi, 2011), program GeoGebra sangat bermanfaat bagi guru maupun siswa. Tidak sebagaimana pada penggunaan software komersial yang biasanya hanya bisa dimanfaatkan di sekolah, Geogebra dapat diinstal pada komputer pribadi dan dimanfaatkan kapan dan dimanapun oleh siswa maupun guru. Bagi guru, GeoGebra menawarkan kesempatan yang efektif untuk mengkreasi lingkungan belajar online interaktif yang memungkinkan siswa mengeksplorasi berbagai konsep-konsep matematis. Menurut Lavicza (Mahmudi, 2011), sejumlah penelitian menunjukkan bahwa GeoGebra dapat mendorong proses penemuan dan eksperimentasi siswa di kelas. Fitur-fitur visualisasinya dapat secara efektif membantu siswa dalam mengajukan berbagai konjektur matematis. Beberapa pemanfaatan program GeoGebra dalam pembelajaran matematika adalah sebagai berikut.. a) Dapat menghasilkan lukisan-lukisan geometri dengan cepat dan teliti dibandingkan dengan menggunakan pensil, penggaris, atau jangka; b) Adanya fasilitas animasi dan gerakan-gerakan manipulasi (dragging) pada program GeoGebra dapat memberikan pengalaman visual yang lebih jelas kepada siswa dalam memahami konsep geometri; c) Dapat dimanfaatkan sebagai balikan/evaluasi untuk memastikan bahwa lukisan yang telah dibuat benar; d) Mempermudah guru/siswa untuk menyelidiki atau menunjukkan sifat- sifat yang berlaku pada suatu objek geometri e) dan Javascript untuk menciptakan media geogebra menjadi lebih interaktif.

Motivasi merupakan kunci dan unsur penting dalam belajar baik bagi siswa maupun bagi guru. Sardiman (2004) mengemukakan bahwa motivasi belajar berfungsi untuk mendorong manusia untuk berbuat, menentukan arah perbuatan dan menyeleksi perbuatan mana yang akan dilakukan. Motivasi belajar juga berfungsi sebagai pendorong usaha dan pencapaian prestasi belajar. Pendapat lain diajukan oleh Dimyati dan Mudjiono (2006) yang menjelaskan pentingnya motivasi belajar bagi siswa diantaranya adalah : a) Menyadarkan kedudukan siswa pada awal belajar, proses dan produknya; b) Memberikan informasi yang berkaitan tentang usaha belajar siswa dibandigkan teman lain; c) Menambah semangat belajar; d) Menyadarkan tentang proses belajar yang kemudian akan dipergunakan untuk bekerja.

Pendapat serupa dikemukakan oleh Hamzah (2007) dan Uno (2008) bahwa terdapat empat peran penting motivasi dalam belajar, antara lain: a) Menentukan hal-hal yang diijadikan sebagai penguat belajar; b) Memperjelas tujuan belajar yang hendak dicapainya; c) Menentukan berbagai macam kendala terhadap rangsangan belajar dan d) Menentukan ketekunan belajar siswa agar hasil belajar menjadi maksimal. Berkenaan dengan fungsi motivasi belajar, Hamalik (2008) menjelaskan bahwa motivasi berfungsi sebagai: a) Pengaruh yang mengarahkan perbuatan seseorang untuk 
mencapai tujuan yang diinginkan; b) Motivasi berfungsi sebagai penggerak berlangsungnya belajar siswa. Berdasarkan uraian diatas peneliti tertarik untuk mengetahui pengaruh aplikasi geogebra berbantuan JavaScript terhadap motivasi belajar siswa dalam pembelajaran matematika materi segitiga.

\section{METODE}

Penelitian ini merupakan penelitian deskriptif kualitatif dengan tujuan menganalisis motivasi belajar siswa dalam pembelajaran matematika materi segitiga dengan berbantuan aplikasi geogebra. Subjek yang digunakan adalah siswa kelas VII di salah satu MTs di Kota Cililin sebanyak 25 orang siswa pada materi segiempat segitiga. Untuk mengukur motivasi belajar dalam pembelajaran matematika siswa diberi angket skala sikap yang terdiri dari pertanyaan positif maupun pertanyaan negatif, sebanyak 10 butir pernyataan.

Untuk mengukur motivasi belajar siswa terhadap pembelajaran matemtika siswa diberi angket dengan skala likert. Jawaban dari pernyataan angket skala likert ada empat, yaitu sangat setuju (SS), setuju (S), netral (N), tidak setuju (TS), sangat tidak setuju (STS). Untuk menghindari kecenderungan siswa memilih netral atau tidak berani memihak maka poin netral dihilangkan, sehingga angket yang digunakan empat skala yaitu sangat setuju (SS), setuju (S), tidak setuju (TS), dan sangat tidak setuju (STS). Teknik pengolahan data yang dipakai dalam penelitian adalah dengan menggunakan Mc.Excel. Data skala sikap yang tadinya berbentuk data ordinal diubah kedalam bentuk data interval menggunakan bantuan Metodh of Succesive Interval (MSI) oleh Mc.Excel. Berikut adalah poin skala motivasi belajar.

\section{Tabel 1.}

Poin Skala Motivasi Belajar

\begin{tabular}{lcc}
\hline \multirow{2}{*}{\multicolumn{1}{c}{ Skala }} & \multicolumn{2}{c}{ Point } \\
\cline { 2 - 3 } & Positif & Negatif \\
\hline Sangat Setuju (SS) & 4 & 1 \\
Setuju (S) & 3 & 2 \\
Tidak Setuju (TS) & 2 & 3 \\
Sangat Tidak Setuju (STS) & 1 & 4 \\
\hline
\end{tabular}

Skala tersebut digunakan untuk mengetahui tanggapan responden terhadap angket yang telah diberikan. Data yang diperoleh kemudian dapat menjadi hasil dari penelitian yang dilakukan. Kemudian hasil penelitian tersebut diklasifikasi berdasarkan kriteria presentase skalanya, berikut tabel skala sikap menurut Riduwan (Rismawati, 2019).

Tabel 2.

Kriteria Klasifikasi Presentase Skala Sikap

\begin{tabular}{cc}
\hline Kriteria $\%$ & Klasifikasi \\
\hline $0 \leq \mathrm{NA} \leq 20$ & Sangat Lemah \\
$20<\mathrm{NA} \leq 40$ & Lemah \\
$40<\mathrm{NA} \leq 60$ & Cukup \\
$60<\mathrm{NA} \leq 80$ & Kuat \\
$80<\mathrm{NA} \leq 100$ & Sangat Kuat \\
\hline
\end{tabular}




\section{HASIL}

Setelah melakukan penelitian di salah satu MTs di Kota Cililin, peneliti menggunakan kelas VII yang memiliki siswa berjumlah 25 siswa sebagai responden. Data yang terkumpul selanjutnya diubah ke bentuk interval, lalu diklasifikasikan berdasarkan kriteria presentase skalanya. Berikut adalah hasil angket yang telah diolah disajikan dalam bentuk tabel:

\section{Tabel 3.}

Hasil Angket Siswa Terkait Motivasi Belajar

\begin{tabular}{clcccc}
\hline NO & Indikator & $\begin{array}{c}\text { Banyak } \\
\text { pernyataan }\end{array}$ & Skor & $\%$ & Kategori \\
\hline 1 & Adanya hasrat dan keinginan untuk berhasil & 2 & 157 & 78,5 & Kuat \\
\hline 2 & Adanya dorongan dan kebutuhan dalam belajar & 2 & 159 & 79,5 & Kuat \\
\hline 3 & Adanya harapan dan cita-cita masa depan & 2 & 148 & 74 & Kuat \\
\hline 4 & Adanya penghargaan dalam belajar & 2 & 153 & 76,5 & Kuat \\
\hline 5 & Adanya kegiatan menarik dalam belajar & 2 & 132 & 66 & Kuat \\
\hline & Total & 10 & 749 & 74,9 & Kuat \\
\hline
\end{tabular}

Berikut deskriptif statistik visual data motivasi belajar dalam pembelajaran matematika

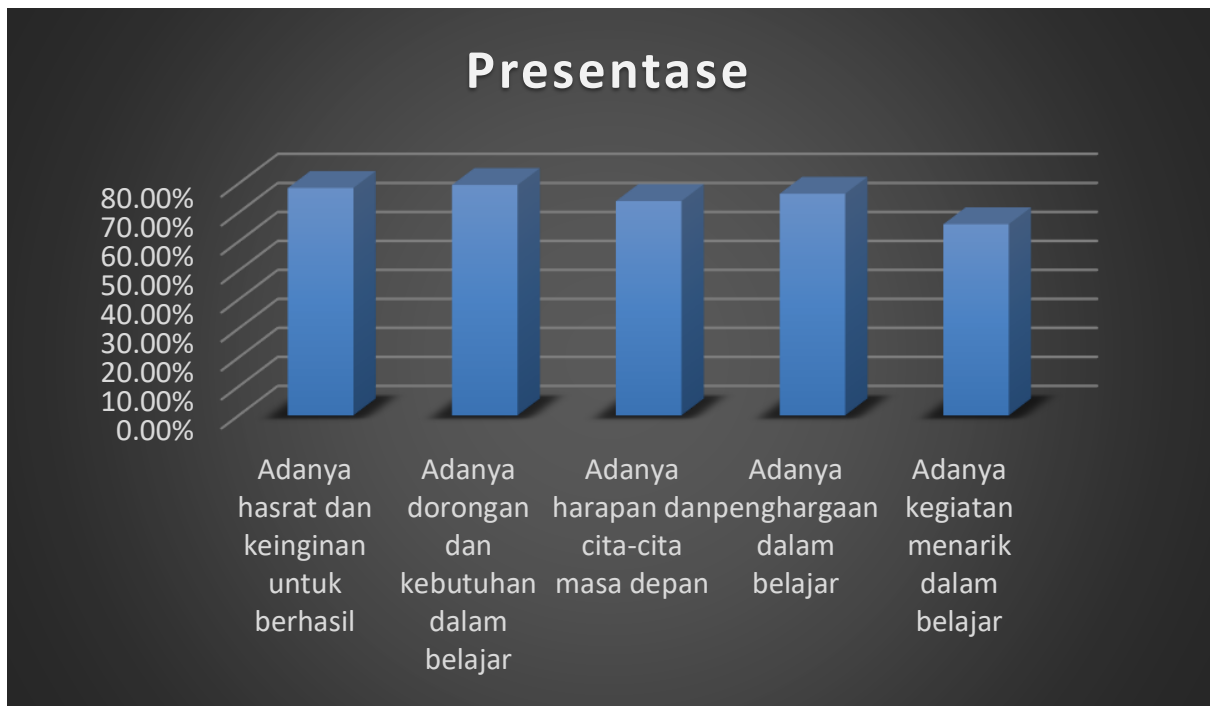

Gambar 1. Diagram Presentase Indikator Motivasi Belajar

Dari gambar 1 dapat dilihat bahwa rata-rata perolehan presentase keseluruhan terkait motivasi belajar sebesar 74,9\% dan dikategorikan kuat. Untuk indikator 1 dengan pernyataan adanya hasrat dan keinginan untuk berhasil presentasenya sebesar 78,5\%. Untuk indicator 2 dengan pernyataan adanya dorongan dan kebutuhan belajar presentasenya sebesar 79,5\%. Untuk indicator 3 dengan pernyataan adanya harapan dan cita-cita masa depan presentasenya

sebesar $74 \%$. Untuk indikator no 4 dengan pernyataan adanya penghargaan dalam belajar presentasenya sebesar $76,5 \%$. Untuk indikator 5 dengan pernyataan adanya kegiatan menarik dalam belajar presentasenya sebesar 66\%. Dari ke lima indikator tersebut semua indikator dikategorikan kuat. 
Siswa diberikan konsep dasar pengetahuan tentang segitiga, dari jenis-jenis segitiga, menentukan jumlah-jumlah sudut segitiga dan menentukan luas segitiga melalui pengamatan dengan menggunakan media javascript geogebra tujuannya siswa mudah memahami secara langsung maskud dari gambar tersebut. Media yang diberikan kepada siswa berdasarkan pernyataan siswa mengenai kesulitan-kesulitan yang ditemui melalui observasi di dalam kelas.

Tabel 4.

Hasil Observasi di Kelas

\begin{tabular}{clcc}
\hline No & \multicolumn{1}{c}{ Pernyataan Materi Segitiga } & Banyak Penguasaan & Presentase \\
\hline 1 & Pengertian segitiga & 5 & $20 \%$ \\
\hline 2 & Sudut-sudut yang berkaitan dengan segitiga & 4 & $16 \%$ \\
\hline 3 & Luas dan keliling segitiga & 8 & $32 \%$ \\
\hline
\end{tabular}

Pada tabel 4, menjelaskan penguasaan prasyarat siswa yang ditemui di dalam kelas terdiri 3 pernyataan yang disampaikan dan hasilnya sebagai berikut a) $20 \%$ banyak siswa yang mampu memahami pengertian segitiga seperti jenis-jenis segitiga berdasarkan sudut dan panjang sisi, b) $16 \%$ jumlah siswa yang mampu memberikan pernyataan jumlah sudut segitiga adalah 180 derajat namun belum dapat memberikan alasan yang tepat, c) 32\% siswa dapat menyebutkan luas dan keliling segitiga namun tidak dapat memahami pengertian tentang luas dan keliling.

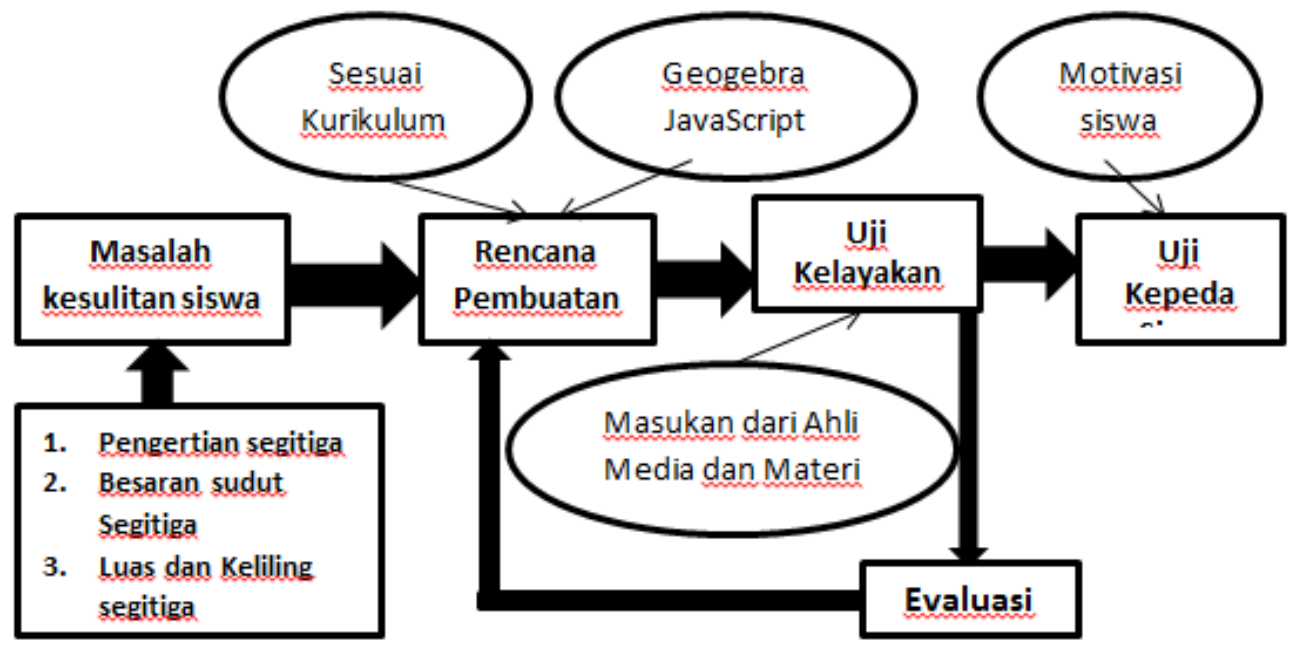

Gambar 2. Rancangan Membuat Media

Gambar 2 menjelaskan alur untuk merancang membuat media pembelajaran matematika pada materi segitiga dengan menggunakan geogebra berbantuan Javascript agar media yang dibuat lebih interaktif. Setelah itu, media tersebut diuji kelayakan berupa masukan oleh ahli media yaitu satu orang dosen yang mengampu mata kuliah Aplikasi TIK Pembelajaran Inovatif Matematika dan ahli materi yaitu satu dosen yang mengampu mata kuliah Kapita Selekta Matematika SMP. 
Tabel 5.

Hasil Masukan dari Ahli Media dan Materi

\begin{tabular}{clc}
\hline Ahli Media & \multicolumn{1}{c}{ Kelayakan Media } & \multicolumn{1}{c}{ Masukan Tambahan } \\
\hline No & \multicolumn{1}{c}{$\begin{array}{l}\text { Membuat Algoritma dalam langkah- } \\
\text { langkah sudah baik }\end{array}$} & $\begin{array}{l}\text { Gambar-gambar yang muncul } \\
\text { diusahakan tidak tumpang tindih } \\
\text { sehingga gambar benar-benar interktif }\end{array}$ \\
\hline 2 & $\begin{array}{l}\text { Membuat Media interaktif dari tombol, } \\
\text { dan gambar sangat bagus }\end{array}$ & \\
\hline 3 & $\begin{array}{l}\text { Menyampaikan konsep segitiga mampu } \\
\text { menciptakan siswa lebih aktif }\end{array}$ & Masukan Tambahan \\
\hline Ahli Materi & \multicolumn{1}{c}{ Kelayakan Materi } \\
\hline No & $\begin{array}{l}\text { Sudah sesuai dengan kurikulum mata } \\
\text { pelajaran matematika kelas 7 }\end{array}$ & $\begin{array}{l}\text { Media dapat memberikan latihan- } \\
\text { latihan secara mandiri atau kelompok. }\end{array}$ \\
\hline 2 & $\begin{array}{l}\text { Media sudah memberikan pemahaman } \\
\text { yang baik berupa langkah-langkah untuk } \\
\text { memecahkan masalah }\end{array}$ & \\
\hline
\end{tabular}

Sesuai masukan dari ahli media dan materi pada tabel 5 merupakan sebagai bahan evaluasi untuk memperbaiki madia pembelajaran matematika dan setelah itu akan diujikan kepada siswa kelas 7 .

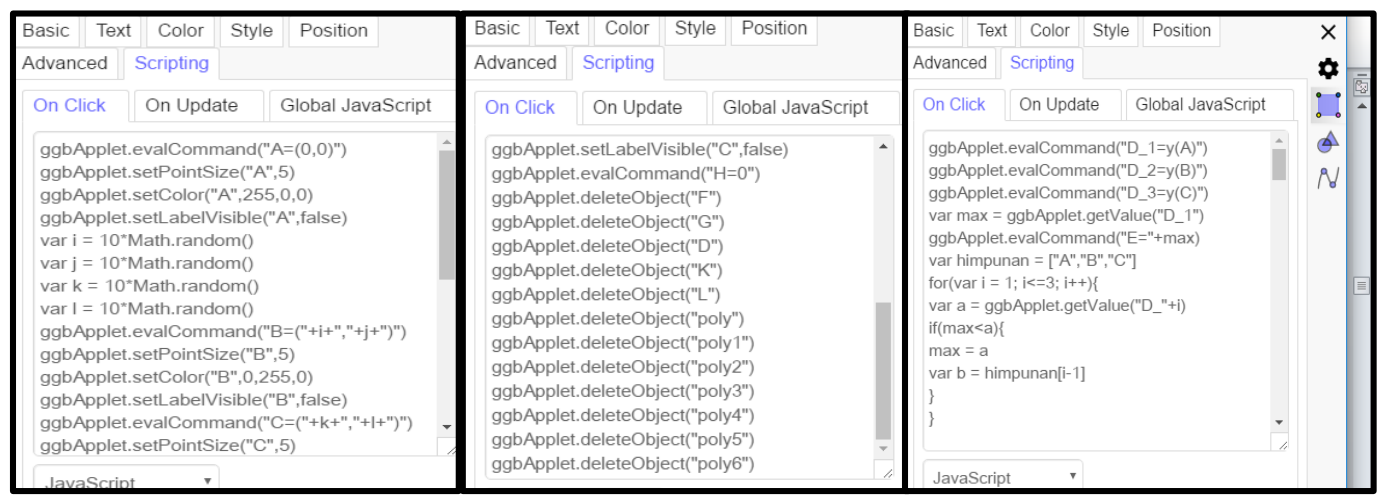

Gambar 3. Membuat Bahasa JavaScript

Gambar 3 menjelaskan algoritma untuk merancang media pembelajaran materi segitiga sesuai masukan dari ahli media dan materi dengan menggunakan bahasa JavaScript dalam geogebra.

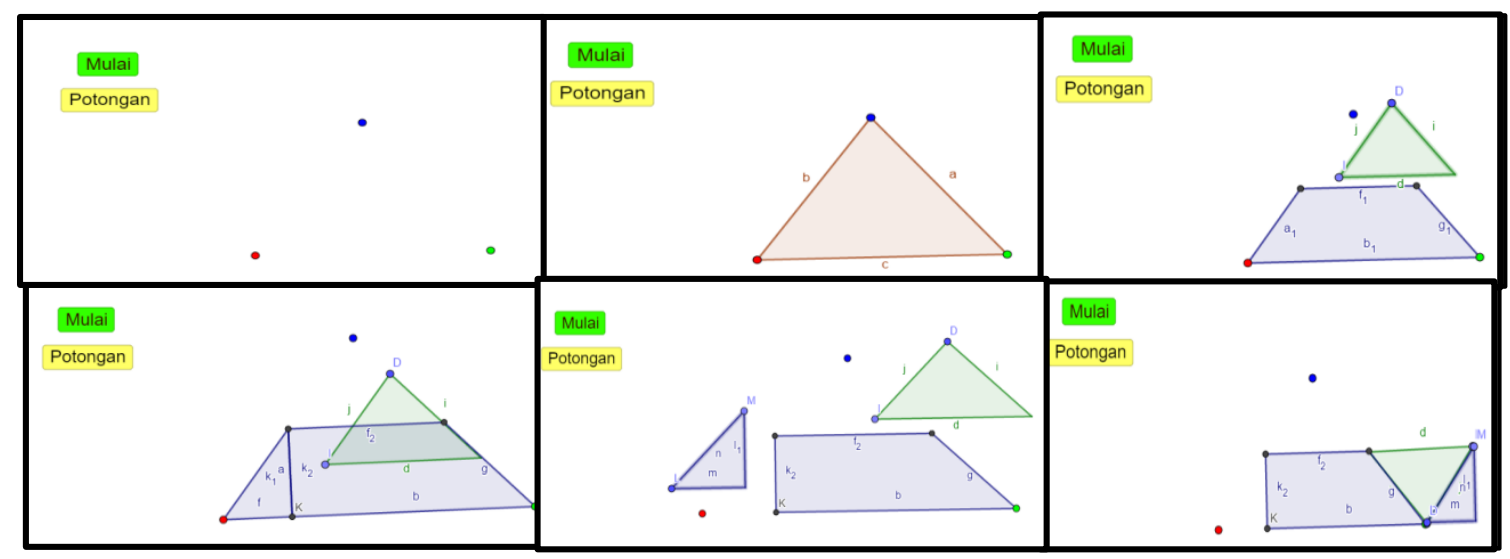

Gambar 4. Hasil Media dari JavaScript Geogebra 
Gambar 4 menjelaskan hasil media pembelajaran matematika menggunakan bahasa JavaScript Geogebra yang menciptakan gambar tesebut berupa langkah-langkah berdasarkan pengetahuan dasar siswa. Dengan media tersebut, Siswa berusaha untuk mendapatkan jawaban sendiri dengan menggeserkan gambar-gambar yang terpotong dan mencocokannya dan setelah itu siswa memberikan kesimpulan dari gambar yang dibuat.

\section{KESIMPULAN}

Dari uraian diatas rata-rata perolehan presentase keseluruhan terkait motivasi belajar sebesar 74,9\% dan dikategorikan kuat. Maka dapat disimpulkan bahwa pengaruh aplikasi geogebra terhadap motivasi belajar siswa dalam pembelajaran matematika materi segitiga dikategorikan kuat. Pengalaman yang didapat oleh siswa dalam pemanfaatan ICT membuat siswa semakin termotivasi dalam belajar.

\section{DAFTAR PUSTAKA}

Al Ayyubi, I. I., Nudin, E., \& Bernard, M. (2018). Pengaruh Pembelajaran Berbasis Masalah terhadap Kemampuan Pemecahan Masalah Matematis Siswa SMA. JPMI (Jurnal Pembelajaran Matematika Inovatif), 1(3), 355-360.

Akbar, P., Hamid, A., Bernard, M., \& Sugandi, A. I. (2018). Analisis kemampuan pemecahan masalah dan disposisi matematik siswa kelas xi sma putra juang dalam materi peluang. Jurnal Cendekia: Jurnal Pendidikan Matematika, 2(1), 144-153.

Bernard, M., \& Senjayawati, E. (2019). Meningkatkan Kemampuan Koneksi Matematik Siswa SMP dengan Menggunakan Pendekatan Metaphorical Thinking Berbantuan Software Geogebra. Jurnal Mercumatika: Jurnal Penelitian Matematika dan Pendidikan Matematika, 3(2), 79-87.

Bernard, M., Sunaryo, A., Tusdia, H., Hendriani, E., Suhayi, A., Parida, M., ... \& Rolina, R. (2019, October). Enhance Learning Independence and Self Ability of Exceptional Children Through Developing Learning Media VBA for Excel Games. In Journal of Physics: Conference Series (Vol. 1315, No. 1, p. 012037). IOP Publishing.

Dimyati dan Mudjiono. (2006). Belajar dan Pembelajaran. Jakarta: Rineka Cipta.

Dwijayanti, I. (2011). Pengembangan Perangkat Pembelajaran Matematika Humanistik Berbasis Konstruktivisme Menggunakan ICT Materi Segi Empat Kelas VII. AKSIOMA: Jurnal Matematika dan Pendidikan Matematika, 2(2/September).

Hamalik. (2008). Perencanaan Pengajaran Berdasarkan Pendekatan Sistem. Jakarta: PT. Bumi Aksara. Hamzah. B. (2007). Teori Motivasi dan Pengukurannya, Aanalisis di Bidang Pendidikan. Jakarta: Bumi Aksara. 
Heris Hendriana, Martin Bernard, M Afrilianto. (2016). Pembelajaran Matematika Melalui Aplikasi Adobe Flash Action Script 2.0: Suatu Pembelajaran Inovatif. Bandung: Refika Aditama.

Hidayat, M. A. 2004. Bahan Penelitian Matematika " Teori-teori Belajar Matematika". Jakarta: Departemen Pendidikan Nasional

Insani, S. U., \& Akbar, P. (2019, October). Development of Open-Ended Based Mathematics Problem to Measure High-Level Thinking Ability. In Journal of Physics: Conference Series (Vol. 1315, No. 1, p. 012047). IOP Publishing.

Isnaeni, S., Ansori, A., Akbar, P., \& Bernard, M. (2019). ANALISIS KEMAMPUAN KONEKSI MATEMATIS SISWA SMP PADA MATERI PERSAMAAN DAN PERTIDAKSAMAAN LINEAR SATU VARIABEL. Journal on Education, 1(2), 309-316.

Kaino, L M. 2008. Information and Communication Technology (ICT) developments, utilization and challenges in ICMI history. www.unige.ch/math/EnsMath/Rome2008/WG4/Papers/KAINO.pdf [31/10/2009].

Kustandi, C., \& Sutjipto, B. (2011). Media Pembelajaran (Manual dan digital). Jakarta: Ghalia Indonesia

Mahmudi, A., \& Negeri, J. P. M. F. U. (2011). Pemanfaatan GeoGebra dalam pembelajaran matematika. In Makalah terdapat pada Seminar Nasional Matematika dan Pendidikan Matematika. Seminar diselenggarakan oleh Jurusan Matematika FMIPA Universitas Negeri Yogyakarta.

Martínez, S. 2005. ICT in Mathematics Education: geometry problem solving with Applets. Recent Research Developments in Learning Technologies. www.formatex.org/micte2005/402.pdf [05/11/2010].

Puspitasari, I. W., Fauzan, G. A., \& Bernard, M. (2019). Penerapan PBL Dengan RME Berbatuan Software Geogebra Untuk Meningkatkan Kemampuan Berpikir Logis Matematik Siswa SMP. Journal on Education, 1(4), 679-687.

Sadirman, A. M. (2004). Interaksi dan Motivasi Belajar Mengajar. Jakarta: Rajawali Press.

Senjayawati, E., \& Bernard, M. (2018). Penerapan model search-solve-create-share untuk mengembangkan kemampuan penalaran matematis berbantuan software Geogebra 4.4. MAJU: Jurnal Ilmiah Pendidikan Matematika, 5(1).

Sugandi, A. I., \& Akbar, P. (2019). Efektivitas Penerapan Strategi React Terhadap Kemampuan Koneksi Matematis dan Self-Efficacy Siswa SMP. Jurnal Cendekia: Jurnal Pendidikan Matematika, 3(2), 431-436.

Sopyan, R., Dewi, M. K., Fauzan, G. A., \& Bernard, M. (2019). Penerapan Pendekatan Realistic Mathematic Education Untuk Meningkatkan Konsep Diri (Self Concept) Siswa Smp Di Era Milenial. Journal on Education, 2(1), 45-42.

Uno, B. H. (2008). Model Pembelajaran. Jakarta: Bina Aksara. 
Analisis Motivasi Belajar Siswa MTs dalam Pembelajaran Matematika Materi Segitiga dengan Berbantuan Media Javascript Geogebra, Martin Bernard, Arif Sunaryo

Wiliawanto, W., Bernard, M., Akbar, P., \& Sugandi, A. I. (2019). Penerapan Strategi Pembelajaran Aktif Question Student Have Untuk Meningkatkan Kemampuan Berpikir Kritis Matematik Siswa SMK. Jurnal Cendekia: Jurnal Pendidikan Matematika, 3(1), 139-148.

Yuwono, M. R. (2016). Analisis Kesulitan Belajar Siswa Kelas VII SMP Dalam Menyelesaikan Soal Materi Segitiga dan Alternatif Pemecahannya. Magistra, 28(95). 